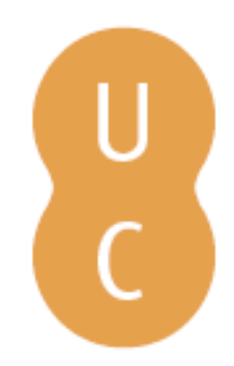

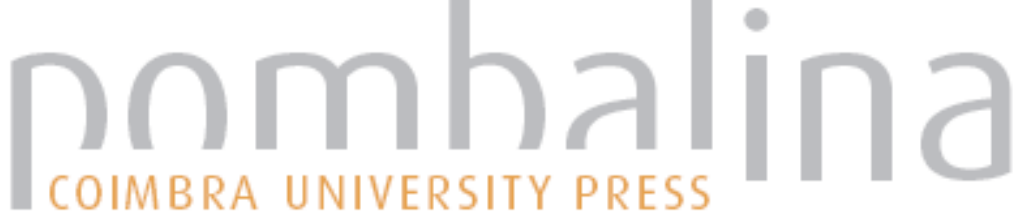

Tiago Veiga: uma biografia (Mário Cláudio): a invenção da verdade

Autor(es): $\quad$ Arnaut, Ana Paula

Publicado por: Imprensa da Universidade de Coimbra

URL

persistente: URI:http://hdl.handle.net/10316.2/38680

DOI: $\quad$ DOI:http://dx.doi.org/10.14195/978-989-26-1164-8_3

Accessed : $\quad$ 26-Apr-2023 12:01:37

A navegação consulta e descarregamento dos títulos inseridos nas Bibliotecas Digitais UC Digitalis, UC Pombalina e UC Impactum, pressupõem a aceitação plena e sem reservas dos Termos e Condições de Uso destas Bibliotecas Digitais, disponíveis em https://digitalis.uc.pt/pt-pt/termos.

Conforme exposto nos referidos Termos e Condições de Uso, o descarregamento de títulos de acesso restrito requer uma licença válida de autorização devendo o utilizador aceder ao(s) documento(s) a partir de um endereço de IP da instituição detentora da supramencionada licença.

Ao utilizador é apenas permitido o descarregamento para uso pessoal, pelo que o emprego do(s) título(s) descarregado(s) para outro fim, designadamente comercial, carece de autorização do respetivo autor ou editor da obra.

Na medida em que todas as obras da UC Digitalis se encontram protegidas pelo Código do Direito de Autor e Direitos Conexos e demais legislação aplicável, toda a cópia, parcial ou total, deste documento, nos casos em que é legalmente admitida, deverá conter ou fazer-se acompanhar por este aviso. 
Ana Paula Arnaut

Universidade de Coimbra / Centro de Literatura Portuguesa

\section{TIAGO VEIGA. UMA BIOGRAFIA (MÁRIO CLÁUDIO): A INVENÇÃO DA VERDADE}

A vida é reinvenção permanente. Tudo é mentira e tudo é real.

Mário Cláudio (Público/Ípsilon)

Há pouco mais de duas semanas, numa aldeia dos arredores de Paredes do Coura, com oitenta e oito anos, faleceu serenamente, após prolongada moléstia esse que se ocultou por décadas e décadas, e que subsistia, até essa altura, entre pinhas e vinhedos e linhas manuscritas, nas maiores das solidões ${ }^{1}$.

Assim começa a crónica sobre a morte de um poeta que se diz ter sido "aclamado, em plena juventude, como o Super-Camões, em texto do autor da Mensagem", cuja cópia Mário Cláudio afirma ter perante si. Assim se inicia um texto que é também, afinal, a notícia, ou melhor, a certidão de nascimento, de Tiago Veiga, o homem e o escritor.

Do homem, descendente "de um minhoto da área de Castro Laboreiro e de uma irlandesa de Dublin", diz-se ter "Aparecido com o século na mesma povoação onde viria a extinguir-se", ter frequentado "o Royal Naval College, em Greenwich" ou ter abalado "para a Guiné, em mil novecentos e trinta e um, integrado numa brigada de luta contra a doença do sono", depois de ter permanecido "algum tempo em Portugal". Não fica sem referência o facto de

1 Mário Cláudio, "Tiago Veiga", in Tempo/Cultura, 18 de agosto, 1988, p. 19. 
ter sido pai de um filho e de uma filha, cujo destino se revelaria tão incomum quanto o seu ${ }^{2}$.

Do escritor, ficamos a saber que, a partir de finais de 1934, se fixaria "em Kilrush, na República da Irlanda, dedicando-se, desde então e exclusivamente, à obra que nos deixou, graças ao apoio de alguns amigos, que haviam formado o círculo de W. B. Yeats". Em termos que traduzem a admiração e o fascínio sentidos pelo autor da biografia, Tiago Veiga surge como o "génio" que deixa inéditos, "como todo o resto", “dois vastíssimos estudos (...) sobre a 'Golden Dawn'”, ou, entre outros escritos, onde se contam "trinta e seis peças", "a insuperável odisseia 'Triunfo e Glória do Arcanjo São Miguel de Portugal'”.

O efetivo reconhecimento literário do poeta acontecerá, portanto, postumamente, com a publicação de Os sonetos italianos de Tiago Veiga, em 2005, livro antecedido da reprodução, "com ligeiras alterações", do artigo que temos vindo a citar e a cujo final Mário Cláudio aduz algumas informações sobre o "conjunto de manuscritos autógrafos, outrora propriedade de Guido Batelli, o conhecido tradutor de Florbela Espanca”.

A publicação desta primeira obra, marcada por um traço decadentista comum a Yeats, parece constituir, então, mais do que a verdadeira saída do anonimato do poeta de quem se diz ter sido "Amparado por Pessoa, em suas primícias"; ela consubstancia, afinal, uma segunda certidão de nascimento de um escritor que a crónica de 1988 não havia conseguido impor na memória (na curiosidade) dos leitores. Não por acaso, pois, Os Sonetos Italianos de Tiago Veiga marcam o início do debate, ou melhor, da polémica, sobre a veracidade da existência do autor de Novecentos ${ }^{4}$.

\footnotetext{
2 "Inverosímil quase se patentearia, refira-se de passagem, o percurso biográfico dessa filha que, nos começos de cinquenta, se exibia, com um número de cavalos, no Circo de Billy Smart, e que, em mil novecentos e setenta e nove, viria a morrer no Convento de Santo António in Polesine, em Ferrara, onde havia professado alguns anos antes. E sabe-se do irmão dela que, tendo sido titular da cadeira de Física Quântica, numa Universidade de Wisconsin, vive ao presente em Washington, é consultor da NASA, formalmente renunciou à herança de seu pai e, há dias, por documento autenticado, aos direitos emergentes das edições de sua vasta obra" (ibidem).

3 Mário Cláudio, Prefácio a Os sonetos italianos de Tiago Veiga. Porto: Asa, 2005, p. 12. Se no artigo do jornal Tempo conhecemos o poeta através de uma fotografia, aqui, a ilustração do homem é feita através da reprodução de um retrato por José Porto (pintura mencionada e reproduzida na Biografia, p. 487 e última da $1^{a}$ série de imagens incluídas entre as pp. 224 e 225).

4 É como alter ego que o entende Ernesto Rodrigues, em artigo intitulado "Poesia portuguesa: uma década "1996-2006)", in http://www.msmidia.com/conexao/3/cap4.pdf (p. 6) (acedido em 9 de janeiro de 2012).
} 
Questionado por Pedro Sena-Lino sobre este facto, Mário Cláudio enreda-nos numa complexa teia sobre desdobramentos de personalidade, figuras reais ou criações de eus poéticos, não permitindo retirar qualquer conclusão definitiva das respostas dadas, mantendo o entrevistador, e a nós com ele, à procura de um Tiago Veiga que, agora, assume ter conhecido, em 1960, e de quem confessa aproximar-se literariamente. Além disso, aproveita para esclarecer "que, na nota que antecede os Sonetos 5 , o poeta aparece como tendo nascido em Castro Laboreiro, mas de facto nasceu em Irajá (Brasil), embora tenha feito crer que tinha nascido lá”. . Ora, relembramos, Castro Laboreiro, nesse texto prefacial (bem como na versão de 1988), aparece como a localidade de origem do progenitor e não de Tiago Veiga, que se diz ter nascido e morrido "numa aldeia dos arredores de Paredes do Coura"”. A questão não parece ser simples, na medida em que, se a página 40 de Tiago Veiga. Uma biografia aponta Irajá como o local de nascimento do biografado, a badana do livro refere o seguinte: "Tiago Veiga nasceu numa aldeia do Alto Minho em 1900, e nesse mesmo lugar viria a morrer em 1988".

Acresce ao exposto que a nota 6 ao primeiro capítulo, "Um menino e um sapato", esclarece (ou confunde):

TV alimentaria ao longo de toda a vida a lenda do seu nascimento em Castro Laboreiro, reivindicando a naturalidade de seu pai, afinal mais conforme à mitificação que insistia em realizar, do Norte profundo de Portugal. Induziria assim em erro o autor da presente biografia, o qual logo no primeiro texto sobre o poeta, publicado no jornal Tempo em 18 de Agosto de 1988, e transcrito no prefácio a Os Sonetos Italianos de Tiago Veiga (...), aceitaria como verdade a

5 O livro subdivide-se em "Seis epitáfios de John Addington Symonds, sumariando seis encontros florentinos" ("Laura", "Girolamo Savonarola", "Tullia d'Aragona", "Tommaso Cavalieri", "Jacopo Carrucci, dito Il Pontormo" e "Giangastone de' Medici"), "Três sextetos do Cardeal Nuno da Cunha de Ataíde, reportando as estâncias maiores de um seu Outono em Roma" (três conjuntos de seis sonetos: "Vasos etruscos", "Bestiário de Óstia" e "O atelier de Bernini"); "Seis cartas em forma de soneto, de Johann Hermann von Riedesel, Barão de Eisenbach, relatando algumas estâncias da sua viagem pela Apúlia"; "Notas" e (índice das) "Ilustrações".

6 Pedro Sena-Lino, "Versos de um muito ninguém", in Público/Mil Folhas, 10 de Dezembro, p. 22 (entrevista).

7 Assim entendemos o sentido das já citadas palavras iniciais do segundo parágrafo: "Aparecido, com o século, na mesma povoação onde viria a extinguir-se, de um minhoto da área de Castro Laboreiro e de uma irlandesa de Dublin (...)”. 
efabulação. Por outro lado o apelido Veiga, não constante do registo de nascimento, seria acrescido, supõe-se que apenas a partir do início da sua idade adulta, ao nome completo (pp. 40/720) ${ }^{8}$.

Ainda que de pouca importância, tendo em conta que semelhantes lacunas sucedem no reconto de outras vidas, a incerteza relativamente a este aspeto suscita, desde logo, a inscrição de uma primeira linha de desconfiança relativamente à efetiva existência do "nosso homem", como, frequentemente, Mário Cláudio designa Tiago Veiga.

Antes de nos debruçarmos, porém, sobre a (re)construção, ou a (re)invenção, da vida deste poeta quase desconhecido, como anuncia a frase que antecede o título da Biografia, cabe, ainda, registar a presença do jogo autoral em Gondelim de Tiago Veiga (2008), e em Do espelho de Vénus de Tiago Veiga (2010). No primeiro título, é-nos oferecida uma história, não só para crianças, de malvadas rainhas, do pássaro Vuldmar e do herói Olderico, enquanto no segundo, como indiciado no pórtico da obra, somos guiados pelos fulgurantes e sufocantes caminhos do amor. Em ambos, a manutenção da ambiguidade: à semelhança do que verificamos no livro de 2005, o nome de Tiago Veiga surge incorporado nos títulos, sendo, agora, seguido, e não antecedido, pela referência, destacada, a Mário Cláudio, a propósito de quem versa, sempre, a nota biográfica da badana. Se em Os sonetos italianos e em Do espelho de Vénus há que ler os respetivos prefácios para conhecermos a atribuição das competências aos dois autores ${ }^{9}$, em Gondelim de Tiago Veiga o esclarecimento advém da folha de rosto: "Leitura de Mário Cláudio / Ilustrações de Albuquerque Mendes".

Não menos interessante neste jogo de ambiguidades é o facto de Boa noite, senhor Soares (2008), de Mário Cláudio, ele só, contar com a menção, ainda que

8 A indicação das citações ou referências feitas a partir deste livro será dada no corpo do texto.

9 Depois de brevemente dar conta da forma como os manuscritos de Os sonetos italianos de Tiago Veiga lhe chegaram às mãos, Mário Cláudio aduz, ainda no prefácio, "que, na leitura a que procedemos, nos limitámos a actualizar a ortografia, sempre de resto extraordinariamente lábil, de Tiago Veiga, e a corrigir um ou outro evidente lapsus linguae. As citações do corpus dos sonetos, exceptuando a da abertura, de Josif Brodski, que é da nossa escolha, foram todas recolhidas, e à data da composição da colectânea, pelo próprio Tiago Veiga". No que diz respeito a Do espelho de Vénus, o texto prefacial, da autoria de José Carlos Seabra Pereira (a menção é feita na capa do livro em conjunto com a indicação de que os desenhos são de Júlio Resende), se, por um lado, sublinha algumas afinidades entre a poesia dos dois autores, por outro lado corrobora a diferença de identidades e, por consequência, o facto de Mário Cláudio ser, apenas, o editor e organizador da coletânea. 
pontual, a Tiago Veiga, no episódio em que António Felício e os companheiros de trabalho comemoram os seus dezoito anos ${ }^{10}$. Por um lado, esta ocorrência pode ser lida como mais uma ficção a aduzir ao jogo de ficções da pessoa de Pessoa presente na novela mas, por outro lado, considerando a eventual existência do poeta de Paredes de Coura, o seu aparecimento em Boa noite, senhor Soares pode consubstanciar uma notável estratégia de veridicção da própria ficção pessoana ${ }^{11}$.

De igual modo, e em conjunto com outras estratégias, não é, apenas, a referência a Fernando Pessoa nas páginas da Biografia que contribui para a criação do efeito de verdade que se pretende criar em torno de Tiago Veiga. Tal como sucede quando se trata de dar conta, por exemplo, das relações do biografado com um vasto grupo de autores nacionais e estrangeiros, e na esteira de um procedimento já usado por Eça de Queirós em A correspondência de Fradique Mendes, a realidade constrói-se pelo relato de encontros vividos. A título de ilustração, transcrevemos o momento em que, no ano de 1926, no Martinho da Arcada, em Lisboa, Tiago Veiga chega à fala com o autor de Mensagem:

Claramente imperava aí Fernando Pessoa, estrela de uma comunidade variável de escritores e artistas, brilhando não pelo clarão do diamante, mas pela sombra da obsidiana. Foi Veiga recebido com a discrição que brindava todo o intruso, e que aliás surgia aconselhada pela natural reserva do jovem, mas por mais do que uma vez endereçar-lhe-ia Pessoa o sorriso que não se afigurava de mera circunstância. Lia ele um manuscrito de poucas páginas, consentindo em que se lhe esboroasse a cinza do cigarro, entalado entre os dedos com que sustinha o papel, e parecia ausente de si mesmo, e dos circunstantes. (...) aproveitando uma pausa na leitura, se puseram a falar com essa volubilidade nervosa, e constelada pela infindável citação de nomes (p. 202).

\footnotetext{
10 Mário Cláudio, Boa noite, senhor Soares. Lisboa: Dom Quixote, 2008, p. 38. Sobre esta obra, ver Ana Paula Arnaut, "Três homens e um livro: Boa noite, senbor Soares de Mário Cláudio", in Soares, Carmen et alii (coords.), Norma E transgressão 2. Coimbra: Imprensa da Universidade, 2011, pp. 201-213.

11 Segundo A. J. Greimas e J. Courtès (Semiótica. Diccionario razonado de la Teoria del Lenguaje. Madrid: Gredos, 1982, p. 432), a transmissão da verdade depende de estratégias epistémicas usadas na cadeia de comunicação: "un creer verdad debe instalarse en los dos extremos del canal de la communicación y a este equilíbrio más o menos estable, a este entendimiento tácito de dos cómplices más o menos conscientes, lo denominamos contrato de veridicción o contrato enunciativo".
} 
Ou, na mesma ordem de ideias, convocamos parte do episódio em que, no mês de janeiro de 1962, Mário Cláudio conhece o autor sobre quem escreve:

Fui descobrir o nosso homem naquilo que lhe servia de gabinete e biblioteca, uma ampla quadra onde se amontoavam livros e papéis, coexistindo com essa confusão de objectos heteróclitos que ajudam a detectar os picos mais notórios de toda uma história pessoal. (...) Abstendo-se de encetar o diálogo, porventura consciente do típico pendor dos escritores aprendizes para dissertar muito mais sobre si próprios, Tiago concedeu-me o tempo necessário à análise discreta do seu habitat. E só quando me viu cravar os olhos no retrato que José Porto desenhara dele, se atreveu a declarar, «Há três décadas, alguém me surpreendeu como sou hoje, e não sei o que isso significará» (p. 487) $)^{12}$.

Mas a grande estratégia de veridicção ${ }^{13}$ consubstancia-se, segundo julgamos, e em termos gerais, na escrita de um extenso volume, cujas cerca de oitocentas páginas nos levam a crer, numa primeira análise e de acordo com uma tipologia genérica, estarmos perante uma biografia académica, caracterizada, na sua essência, por um recurso excessivo ao pormenor. No caso em apreço, este traduz-se numa dimensão subjetiva que aponta para a biografia ficcionalizada, designação que preferimos à de ficção biográfica ${ }^{14}$ (de acordo com a ênfase que nos parece que Mário Cláudio pretendeu pôr no verdadeiro registo de uma vida), ou à de biografia literária, apesar de o conceito parecer adequar-se a Tiago Veiga. Uma biografia, na medida em que, na sua dualidade de aceções, ele respeita tanto às vidas de homens e mulheres da área da Literatura quanto ao uso de um estilo afim do usado no registo literário ficcional ${ }^{15}$.

12 Os laços a criar entre ambos são anunciados quase nas páginas iniciais, quando se cita o conteúdo de uma das cartas que Tiago Veiga escreveria a Mário Cláudio (cf. p. 51). Relembramos que na já citada entrevista a Pedro Sena-Lino (nota 6), Mário Cláudio afirma ter conhecido Tiago Veiga em 1960 e não em 1962.

13 Num outro plano, a título de curiosidade, registe-se que "o nosso homem" é dado como tendo pertencido, na Guiné, ao grupo de amigos do avô materno de João Rasteiro, autor de uma recensão, ainda inédita, a Tiago Veiga. Uma biografia ("Poetas: Tiago Veiga, meu avô e eu!).

14 The world book encyclopedia. Chicago: World Book, 1976, vol. 2 ("Biography").

15 Ver, a propósito, Donald J. Winslow, Life-writing. A glossary of terms in biography, autobiography, and related forms. Honolulu: Biographical Research Center/University of Hawii, 1980, p. 25. 
Seja como for, dando cumprimento às expetativas criadas pelo género em causa, Mário Cláudio apresenta o percurso do protagonista do nascimento até à morte ${ }^{16}$, num relato em que, de modo sistemático, objetivas referências cronológicas emolduram os seus ascendentes e descendentes, as suas amizades e os seus ódios, os seus amores e os seus desafetos, as suas manhas e as suas virtudes, enfim, a sua vida pessoal sempre misturada com a sua vida literária ${ }^{17}$. No entanto, a linha de objetividade que referimos é sempre colorida por comentários de elevado teor de subjetividade e, por isso, no âmbito de uma estratégia subversiva muito curiosa, é possível verificar a existência de várias menções que, praticamente desde o início, convocam a imagem criada por Richard Holmes sobre o biógrafo.

Diz o ensaísta inglês que "there is something frequently comic about the trailing figure of the biographer: a sort of tramp permanently knocking at the kitchen window and secretly hoping he might be invited in for supper"18. À semelhança, pois, do que lemos em Amadeo $(1984)^{19}$, ou de outras suas biografias, Mário Cláudio vai intrometendo-se na vida que relata com tal subtileza que, a dado momento, biografia e autobiografia - e, por que não, autorbiografia ${ }^{20}$ - quase parecem fundir-se e confundir-se. Deste modo, as primeiras linhas de Tiago Veiga. Uma biografia ao mesmo tempo que informam sobre a localização geo-

16 Segundo Catherine Peters, "Secondary lives", in John Batchelor (ed.), The art of literary biography. Oxford: Clarendon Press, 1995, p. 44, "The biographer, like any romantic novelist, believes in the importance of a central character and a strong and logically connected narrative which - give or take a modish disruption or two, usually to the opening scene - proceeds from cradle to grave in an unbroken arc".

17 Veja-se, a propósito, a súmula dos "vários «itinerários» (...) de Tiago Veiga” feita por Álvaro Manuel Machado em "Tiago Veiga - Uma biografia”, de Mário Cláudio. Imaginário heteronímico e espírito do lugar", in Colóquio Letras, no 179, janeiro-abril, 2012, pp. 199-204.

18 Richard Holmes, Footsteps. Adventures of a romantic biographer. New York: Elisabeth Sifton Books, 1985, p. 144.

19 Sobre o assunto, ver, Ana Paula Arnaut, Post-Modernismo no romance português contemporâneo. Fios de Ariadne-máscaras de Proteu. Coimbra: Almedina, 2002, pp. 176-198.

20 Retiramos a expressão de Luigi Cazzato, "Hard metafiction and the return of the author-subject: The decline of postmodernism?", in Jane Dowson and Steven Earnshaw (eds.), Postmodern subjects. Postmodern texts. Amsterdam-Atlanta, GA: Rodopi, 1995, pp. 35-36: "In hard metafictional novels, the anxiety we are talking about may be classified according to the factors of the literary communication that are most predominant. Addresser (the author): the author-narrator becomes a character, thus expressing an anxiety about the authenticity of the story (it is what can be called authorbiographic mode). Message/context (history): the author-narrator becomes a historian in order to express an anxiety about the manipulation of history (bistoriographic mode). Adressee (the reader): the author-narrator becomes a critic, finally expressing an anxiety about the destiny of his/ her message (criticgraphic mode)" (itálicos do autor). 
gráfica em que parte da vida do poeta decorrerá (a Casa dos Anjos, em Venade, freguesia de Ferreira, concelho de Paredes de Coura), procedem, de imediato, à inscrição de quem, nos bastidores, tudo controla. Atente-se, por exemplo, na referência a que "Um dos episódios maiores na história da Casa dos Anjos consta de um relato que, se não valer pelo seu literário desempenho, poderá servir os agentes naturais que vierem a visitá-lo" (p. 29).

Numa estratégia idêntica à de quem, por enquanto, apenas bate à janela da cozinha, para retomarmos a imagem de Richard Holmes, o relato aqui referido é explicitado em nota final (p. 719). Esta remete para "A menina dos anjos", um dos contos de Itinerários (1993), da sua autoria, em que delega no escritor Camilo Castelo Branco o estatuto de narrador dos "factos" que, com pequenas variações-omissões ${ }^{21}$ e os necessários acrescentos, virão a consubstanciar o primeiro capítulo da Biografia, intitulado "Um menino e um sapato". Procedimentos semelhantes acontecem quando Mário Cláudio confessa ter recolhido, "obtida a adequada autorização", um dos versos deixado de lado por Tiago Veiga, "numa dessas colectâneas obscuras que se afoitou a dar à estampa" (p. 56), e que a nota 6 a este capítulo (p. 720), "Os alfabetos da bruma", esclarece tratar-se de Dois Equinócios (1996). O verso em causa é o quinto do poema "Amanita Muscaria", que transcrevemos:

Ao toque do chifre,

Por onde a espuma da cerveja iam bebendo,

Mascavam os do Norte o cogumelo mortal.

Para a pilhagem,

O relâmpago de marfim e oiro lhes submergia a face.

Para o estupro,

A enseada de rochas e abetos lhes dilatava o coração.

Não fica sem menção o facto de Boa noite, senhor Soares resultar do aproveitamento de um episódio relatado por Tiago Veiga aquando do regresso da

${ }^{21}$ Leonel, pai de Inácio Manuel, progenitor de Tiago Veiga não é, aqui, dado como o filho do escritor de Oitocentos e de Ana Plácido (Nuno Plácido).

Em Itinerários encontra-se também "Balada para Hilda Blum" (pp. 21-23), senhora, personagem, que Mário Cláudio apresenta a Tiago Veiga na tentativa de o levar a superar "a desolação" em que Tobby o deixara (p. 589) (ver nota 6 do capítulo "O guarda-vento do Waldorf Astoria”, p. 769). 
Guiné, aos 5 de abril de 1933 (pp. 265-266) (nota 17, capítulo "Ofício tropical", p. 739), ou, ainda, a referência a que "O empolgamento de TV pela figura de Guilhermina Suggia seria determinante da escrita de Guilhermina" (p. 739) (nota 4, capítulo "Regresso ao clã", p. 739), romance que, como outros, Mário Cláudio lhe ofereceria, sem, contudo, lograr receber o "cartãozinho de boas maneiras (...) a agradecer o obséquio da oferta, e a prometer solenemente as suas impressões para mais tarde" (p. 662) 22 .

A efetiva entrada do biógrafo na intimidade da casa a cuja janela vinha batendo dá-se, sensivelmente, a meio da Biografia, poucas páginas antes de sabermos do já referido momento em que as vidas dos dois autores se cruzam. Com efeito, a partir do capítulo "O pássaro bisnau", inaugural do terceiro grande bloco da obra (p. 481), Mário Cláudio penetra numa casa duplamente significativa: porque remete para um espaço físico e, em concomitância, para o convívio com Tiago Veiga, e porque remete para a própria narrativa.

A inscrição do eu nas páginas subsequentes será, portanto, completamente desassombrada de constrangimentos não apenas no que diz respeito, num primeiro plano, à formulação de juízos de valor sobre várias atitudes do biografado (literárias ou outras). Estes comentários, potencializados e intensificados pela proximidade pessoal e afetiva que acabamos de registar, levam à diluição da "objetividade que se presume de um biógrafo" (p. 501) e reforçam, também, a hipótese de identificarmos certas passagens com o que Catherine Peters designa como "biografia ventríloqua": "one in which the biographer seeks to annihilate the distance between self and his subject by taking on the subject's own voice"23.

Patente desde as primeiras páginas, através de um registo manifestamente evidenciador da admiração sentida pelo "nosso compatriota" (p. 503), por quem se sente responsável (p. 593) e por quem nutre verdadeiro afeto, apesar de confessar tê-lo amado "tão mal" (p. 705), a primeira situação pode ser ilustrada através de diversos exemplos. Entre outros, quando o autor identifica Tiago Veiga como um "Cão velho, farejando", em Inglaterra, "o rasto do cio da (...) jovem

22 Entre outras intromissões do género, registe-se, ainda, que, na p. 592 (ver nota 9, p. 769, do capítulo indicado na nota anterior), Mário Cláudio cita um excerto do seu terceiro romance, Damascena (p. 59), dando conta de um monólogo de uma misteriosíssima personagem ("The Ambassador") que terá observado no hotel londrino em que se encontrava com Tiago Veiga.

23 Catherine Peters, art. cit., p. 45. 
cadelita” (p. 583), Tobby, a rapariga que, em Venade, tomara sob sua proteção (p. 566), ou quando, agudizando-se a "discórdia que sempre latente palpitara" entre ambos, refere

A maníaca obsessão com que se lançava em tais exórdios ${ }^{24}$, brandindo números que se reportavam a rubricas variadas, "contra-corrente», «apuro de venda de bouças e pinhais", "o que herdei de Ellen", "gastos com o telhado e a pintura interior da capela», "despesas com a minha saúde», etc., etc., confirmava as suspeitas que eu entretinha quanto à manifestação dos indícios de um progressivo amolecimento mental que diversas evidências todavia desmentiam. Mantinha ainda Tiago de facto o integral domínio do verbo escrito, não se mostravam raras as afirmações do seu velho humor, e fortalecia-se nele o a-propósito da condenação acerba dos desconchavos do mundo (pp. 600-601).

Quanto à segunda circunstância, respeitante à anulação da distância entre o eu e o outro, numa estratégia em que as vozes se misturam, podemos chamar à colação as considerações feitas sobre o facto de Tiago Veiga se sentir "na pele de um leproso miraculado, mas só temporariamente limpo de toda a chaga" (p. 563), ou a reflexão que, durante uma viagem à Galiza, o biografado faz sobre o destino que ele e Tobby ali cumpririam (p. 570). Neste âmbito, é também interessante convocar um excerto em que a exemplificação do 'ventriloquismo' decorre do uso de uma ekphrasis ${ }^{25}$ que espelha o nomadismo do escritor (passim), a indiferente e distante relação deste com a filha, Judith dos Anjos, e com a primeira mulher, Jeanne Chazot (pp. 170-182), ou o caráter errante que irá caracterizar o percurso vivencial da primogénita (pp. 308, 334, 409, 440, 448, 454, 493, 638, 709). Em última análise, ainda, o efeito de representação que se

24 As invetivas decorrem do facto de Mário Cláudio, no desempenho de funções de servidor do Estado português, não ter incluído o nome de Tiago Veiga "no rol dos beneficiários" de subsídios a atribuir "aos trabalhadores das artes e letras, e de uma forma geral aos agentes da cultura" (p. 600).

25 De acordo com Luís Quintais, "Sendo uma representação verbal de uma representação visual, dir-se-ia que a ekphrasis trabalha esse hiato entre formas de representação diferenciadas. Celebra a impossibilidade de transporte, mas ironicamente procura uma consistência, afirmando, afinal, o mistério ou a inquietação ou o desassossego dessa impossibilidade", "A ekphrasis como meta-representação", in Relâmpago, no 23, 2008, p. 95. 
obtém pela ekphrasis remete para o destino de um poeta, sempre saltimbanco, cujo destino de escrita (p. 705) jamais de cumprirá. A citação é, pois, longa mas necessária:

A cortina que a pequena Judith levantara sobre o universo do circo, prefigurado naquele malabarista do Quai Voltaire, prolongaria por algum tempo o consórcio do nosso poeta com Paris. Recordava-se ele do incipit da quinta das Elegias de Duino ${ }^{26}$, a qual lhe constava ter sido inspirada por um quadro de Picasso, o Acrobata sobre Uma Bola, que o poeta alemão temporariamente albergara no seu quarto parisiense. De Rilke passara Tiago por isso aos trabalhos circences do grande pintor, e era como que por milagre que se via, e ao seu contexto, representado em três óleos de 1905. Na Família de Acrobata com Macaco identificava-se com o palhaço pobre, inclinado para a menina que Jeanne tinha ao colo, e contemplava-os a simiesca imagem do destino, tristissimamente ameaçadora. O Acrobata sobre Uma Bola, obra que desencadeara a tal composição do autor das Elegias de Duíno, lembrava-lhe em que poderia volver-se a filha pré-adolescente, votada à errância sem fim, e treinando o equilíbrio diante de um atleta torcionário que a escravizava. E observa-se a si mesmo na Família de Saltimbancos, envergando um maillot de arlequim, confortando o próprio progenitor que se convertera num clown gordo, e dando a mão a uma Judith dos Anjos transformada em fragilíssima funâmbula. O mundo era exactamente aquilo (p. 182).

Mas o mais interessante e notável efeito resultante da insistência progressiva na inscrição do eu, isto é, de si, Mário Cláudio, reside, num segundo plano, no facto de este acabar por se sobrepor ao registo do outro, dessa forma nimbando a biografia de marcas de autobiografia. Assim, como acima já sugerimos, a leitura

26 "Mas quem são eles, dizei-me, os errantes, esses um pouco / mais fugazes ainda que nós mesmos, e que, desde cedo / contorce urgente, num para quem, por amor de quem, uma / vontade jamais nunca satisfeita? / Mas contorce-os, / curva-os, enlaça-os, fá-los vibrar, / arroja-os, recupera-os; como de um ar oleoso, / mais liso, descem / sobre o tapete esfiado, mais delgado / do seu eterno salto, esse tapete / perdido no universo. / Colocado como um penso, como se o céu-/-arrabalde aí tivesse magoado a terra. (...)" (Rainer Maria Rilke, Elegias de Duíno: os sonetos a Orpheu. Trad. Vasco Graça Moura, pref. João Barrento. Lisboa: Bertrand, 2007, p. 41. 
dos capítulos que se seguem a "O pássaro bisnau" revela que o biógrafo faz sua a casa de uma narrativa que se esperaria ser apenas do biografado. A narrativa heterodiegética passa, então, a ser sistematicamente intersecionada pelo relato de episódios em que sobressaem variadas marcas autodiegéticas. A sensação com que ficamos, tratando-se, naturalmente, de um dado subjetivo, é a de que, a partir deste momento, a vida que seguimos é a do biógrafo, sendo o percurso do biografado convocado a propósito desta.

Um percurso, ou melhor, o relato de um percurso, que Mário Cláudio assume acabar por escrever mediante pedido de Tiago Veiga:

"Vais agora escrever-me a biografia», começou a planear, "servindo-te das conversas que tivemos até hoje, e daquelas que haveremos de ter, e do que a tua fantasia engendrar para preencher as lacunas». E tirando partido da minha atónita imobilidade, explicou o nosso poeta, "Nada desse truque com barbas dos papéis achados, ou entregues, mas um corajoso embuste, apoiado nos teus movimentos da alma, e nos teus ímpetos do coração». "É claro», preveniu ele, "que irão acusar-te de me teres inventado, considerando-se muito argutos pela descoberta, mas não será verdade que cada biógrafo inventa o seu biografado, e que andamos todos nós a inventar-nos uns aos outros?». De resto», acalmou-me por fim, "a tua invenção só poderá manifestar-se parcialmente na minha existência, e na lógica que souberes colocar no retrato, isto porque no tocante à minha autenticidade física, e por muito embrulhados no anonimato que hajam decorridos os meus dias, não faltam por aí provas nas conservatórias, nos cartórios, e no testemunho de quantos me conheceram, e que, morto eu, não deixarão de ser os primeiros a vir à ribalta depor (...). «Vais, portanto, escrever a minha biografia, meu caro», intimou Tiago, e logo acrescentaria isto que me gelou, «ainda que neste minuto imediato me respondas que não» (p. 650).

A recusa perentória (pp. 657, 658, 660) ao encargo surge, inicialmente, apenas depois de outros assaltos em forma de ordem mas parece não ser suficiente para dissuadir Tiago Veiga do projeto (cf. p. 678). Um projeto que, afinal, Mário Cláudio levará a bom termo, não resistindo ao espicaçamento do apetite (p. 710) e à nostalgia do convívio com a matéria biográfica (p. 691), ou, se quisermos, 
com a "imaginação biográfica»", já presente em romances anteriores e agora definitivamente transformada em "imaginário heteronímico"27.

Mas retornemos ao excerto citado, importante não só porque nele se escreve, se assume, a impossibilidade de uma objetividade total no relato e, por conseguinte, de uma linguagem absolutamente transparente, como escreveu Michel Foucault ${ }^{28}$. A passagem acima é também relevante porque nela se retoma, pela própria voz da pessoa biografada (criada), a suspeita sobre a sua veracidade enquanto entidade civil, ou se preferirmos, pelo que nela existe de autorreferência sobre o seu estatuto de ser, de homem, meramente de papel, apesar de, como afirma, "não faltarem por aí provas, nas conservatórias, nos cartórios". Se nas palavras de Tiago Veiga lemos que "cada biógrafo inventa o seu biografado", pelas de Mário Cláudio sabemos que

Todas as biografias são ficção. Todos os romances têm biografias dentro de si. Foi por isso que ele me pediu uma biografia não-científica. A biografia como processo metodológico de inventar um interior de uma vida acaba por ser muito mais verdadeira do que aquela que se cinge aos factos e à mera cronologia. Ele sabia que eu nunca faria uma biografia meramente factual. Sou incapaz de desinventar completamente uma vida. Um exercício de desinvenção é algo profundamente desumano e para mim impraticável ${ }^{29}$.

Do que se trata, portanto, em conjunto com as estratégias que temos vindo a referir, é de criar um jogo em que a invenção das fragilidades interiores da criatura, sendo feita à semelhança das debilidades que reconhecemos no ser humano, acaba por desvanecer a hipótese de nela lermos um ser excecional,

27 Álvaro Manuel Machado, "TTiago Veiga - Uma biografia», de Mário Cláudio. Imaginário heteronímico e espírito do lugar", art. cit., p. 197. A recorrência do elemento "iimaginário biográfico"” (que leva a que algumas personagens possam ser vistas como máscaras do autor) em conjunto com um "iimaginário do lugar" foi inicialmente assinalada na recensão a Amadeo, publicada no jornal Semanário de 20 de abril de 1985 e posteriormente reproduzida em A abertura das palavras. Ensaios de literatura portuguesa. Lisboa: Presença, 2007, pp. 145-149. Sobre o "iimaginário do lugar”" ou "«espírito do lugar» (em particular um imaginário do Norte, entre o Porto e o Minho, herdado em grande parte de Agustina)", o ensaísta esclarece que este "frequentemente se concentra no "espaço encantatório" da casa relacionado com o complexo mecanismo da infância".

28 Michel Foucault, Les mots et les choses. Paris: Gallimard, 1966, p. 133.

29 "Sou incapaz de desinventar completamente uma vida", entrevista de Rui Lagartinho, in Público/ Ípsilon, http://ipsilon.publico.pt/livros/entrevista.aspx?id=288369 (acedido em 18 de janeiro de 2012). 
mais fácil de encontrar na ficção do que na realidade em que vivemos. Também por isso, como diz,

À semelhança do que me ocorrera em anteriores ocasiões, nem sequer seria a peregrinação de Veiga por este mundo que sobremaneira me importava, mas o cenário de atmosferas em que a mesma se desenrolara, a acrescer aos inegáveis factores de relevância intelectual, o seu assumidíssimo anonimato, e as múltiplas facetas de uma obra que, estilhaçada embora, se imprimia com tamanha originalidade no contexto da nossa literatura. O que para a fantasia me ficava, e era imenso, jamais precludiria o engenho de um criador que tão-só os críticos suspeitosos da realidade física que lhe cabia se obstinariam em negar, ou em aceitar com reticências (p. 692).

A atenção prestada ao "cenário de atmosferas" e a outros miúdos pormenores, idênticos a esses "pequenos-nadas quotidianos" de que nos fala em "Proustofilia", uma das crónicas publicadas em O eixo da bússola (2007), será de fundamental importância na (re)criação da vida e do mundo que, agora, é o de Tiago Veiga e não o de Marcel Proust, como sucede no texto em cujas páginas lemos o gosto de Mário Cláudio pelas particularidades do universo do autor francês. "Os proustofílicos", escreve, "serão sempre celebrantes dos dias, curiosos do acaso, explicadores de lances (...)"30 e o que poderíamos considerar um excessivo recurso a detalhes acaba por consolidar, afinal, o efeito de verdade que perpassa as páginas de Tiago Veiga. Uma biografia.

A estratégia não é, então, recorrer "àquele truque dos romancistas que consiste em colocar-se no exterior dos acontecimentos, a fim de os observar com a curiosidade possível” (p. 675), mas, antes, colocar-se no seu interior e observá-los com a curiosidade necessária e inevitável a quem tem por tarefa inventar vidas.

Não nos parece, contudo, que a invenção levada a cabo, por oposição à "desinvenção", seja critério praticamente exclusivo para afastar a criação claudiana do conceito de heteronímia, como afirma na entrevista conduzida por Rui Lagartinho e em que, aliás, reafirma a existência, em "carne e osso", de Tiago Veiga. Citamos:

30 Mário Cláudio, O eixo da bússola. Vila Nova de Famalicão: Quasi, 2007, p. 115. 
- Porque inventa e não desinventa, podemos concluir que de facto Tiago Veiga nunca pode ser visto como um heterónimo do biógrafo Mário Cláudio...

- Os heterónimos são essa tal desinvenção. Veja-se o caso de Fernando Pessoa com as mini biografias que criou para os seus heterónimos. São esquemáticas e não nos permitem saber nada sobre a forma como eles funcionavam por dentro. Quem eram as mulheres da vida de Ricardo Reis, ou os homens da vida de Álvaro Campos? Sabemos apenas algo, pouco, sobre a sua diversa orientação sexual. Eu não quis esterilizar a vida de Tiago Veiga. Qualquer pessoa é o que ela pensa, o que ela imagina, a sua atmosfera, o ar que respira, em que vive. A sua aura. Tiago Veiga é uma figura de carne e osso. Não é um heterónimo. Quem tiver dúvidas pesquise, vá aos cartórios.

Ora, se o grande fator de constituição heteronímica, isto é, se o grande fator de autonomização da criatura (no caso de Fernando Pessoa, das criaturas) se consubstancia, principalmente, na atribuição de um estilo de escrita diverso daquele que caracteriza a produção literária do criador, então, Tiago Veiga pode e deve, de facto, ser entendido como um heterónimo, ou, pelo menos, como um semi-heterónimo ${ }^{31}$. Mas, retomemos o jogo e admitamos, ainda que por breves instantes, que o poeta de Novecentos não é uma criação, não é um heterónimo, e coloquemos novamente o problema da sua existência real. A verdade é que, talvez, este não seja um problema, já que a própria Biografia se encarrega de nos fornecer algumas pistas importantes para o desvendamento da dúvida instaurada na crónica de 1988 e mantida até à data nas várias entrevistas dadas por Mário Cláudio.

Por um lado, relembramos, temos acesso a todo um manancial de informações que contribuem para o que Roland Barthes designou, há muito, por "efeito de real"32: entre outros, a moldura histórico-social, onde se conta a transcrição de notícias de jornais ${ }^{33}$, ou as referências a dados guardados em cartórios, existência de epistolário com figuras reais, reproduções de pinturas

\footnotetext{
31 Ver supra, nota 9: no prefácio a Do espelho de Vénus José Carlos Seabra Pereira sublinha algumas afinidades entre a poesia dos dois autores, não procedendo, no entanto, a uma identificação total.

32 Roland Barthes, "L'éffet de réel", in Communications, n 11, 1968, pp. 84-89.

33 Assim sucede na p. 70, em que a nota 8 (p. 721) remete para uma notícia de $O$ dia, de 11 de maio de 1911 (palavras do republicano Magalhães Lima).
} 
e de fotografias (de Tiago Veiga, de familiares e de amigos ou conhecidos). Por outro lado, no entanto, a suspeição consolida-se a vários níveis: pelo jogo autoral a que já nos referimos a propósito dos livros publicados de Tiago Veiga, porque os documentos que atestam/atestariam a existência do "nosso homem" estão no segredo de longínquos cartórios, porque alguns bilhetes se encontram extraviados (p. 290 / nota 4, p. 741 34), porque, em última instância, o espólio veiguiano que sobreviveu ao seu ímpeto destrutivo ${ }^{35}$ (pp. 484, 563, 663, 678, 714, por exemplo) se encontra em diversos arquivos pessoais, aos quais não existe fácil e livre acesso. Entre estes arquivos conta-se o de Mário Cláudio, a quem cabe o derradeiro controlo sobre a publicação dos escritos e (tal como sucede no caso de Pessoa, cf. p. 223), o papel de senhor do heterónimo Tiago Veiga. Um heterónimo que não sendo embora um homem de corpo físico é, seguramente, um homem de alma e de vontade completas.

34 Alusão aos bilhetes trocados entre Inácio Manuel dos Anjos e Tiago Veiga, por ocasião do regresso do primeiro a Paredes de Coura. Extraviadas se encontram também as obras de Ellen Rassmunsen, primeira mulher de Tiago Veiga (p. 354, nota 9, p. 745).

35 Ímpeto destrutivo, também, de Mário Cláudio. A nota 16 da p. 492 (p. 760) esclarece que a carta citada, de Tiago Veiga para o autor da Biografia, é "uma das poucas" que "se dispensou de destruir, animado pelo sarcasmo de tom com que o poeta julgava confortá-lo". 


\section{BIBLIOGRAFIA}

ARNAUT, Ana Paula, (2011), "Três homens e um livro: Boa noite, senhor Soares de Mário Cláudio", in Soares, Carmen et alii (coords.), Norma \& transgressão 2. Coimbra: Imprensa da Universidade, pp. 201-213.

(2002), Post-Modernismo no romance português contemporâneo. Fios de Ariadne-máscaras de Proteu. Coimbra: Almedina.

BARTHES, Roland, (1968), "L'éffet de réel", in Communications, no 11, pp. 84-89.

CAZZATO, Luigi, (1995), "Hard metafiction and the return of the author-subject: The decline of postmodernism?", in Jane Dowson and Steven Earnshaw (eds.), Postmodern subjects. Postmodern texts. Amsterdam-Atlanta, GA: Rodopi.

CLÁUDIO, Mário, (2011), Tiago Veiga. Uma biografia. Lisboa: D. Quixote.

(2007), O eixo da bússola. Vila Nova de Famalicão: Quasi.

(1996), Dois equinócios. Porto: Campo das Letras.

(1993), Itinerários. Lisboa: Dom Quixote.

(1988), "Tiago Veiga", in Tempo/Cultura, 18 de agosto, p. 19.

CLÁUDIO, Tiago, (1983), Damascena, Lisboa: Contexto.

GREIMAS, A. J. / COURTÈS, J., (1982), Semiótica. Diccionario razonado de la teoria del lenguaje. Madrid: Gredos.

HOLMES, Richard, (1985), Footsteps. Adventures of a romantic biographer. New York: Elisabeth Sifton Books.

LAGARTINHO, Rui, "Sou incapaz de desinventar completamente uma vida". Entrevista com Mário Cláudio, in Público/Ípsilon, http://ipsilon.publico.pt/livros/entrevista. aspx?id=288369 (acedido em 18 de janeiro de 2012).

LINO, Pedro Sena (2005), "Versos de um muito ninguém". Entrevista com Mário Cláudio, in Público/Mil Folhas, 10 de Dezembro, pp. 22-23.

MACHADO, Álvaro Manuel, (2012), "Tiago Veiga - Uma biografia», de Mário Cláudio. Imaginário heteronímico e espírito do lugar”, in Colóquio Letras, n 179, janeiro-abril, pp. 197-204.

, (2007), A abertura das palavras. Ensaios de literatura portuguesa. Lisboa: Presença, pp. 145-149.

PETERS, Catherine, (1995), "Secondary lives", in John Batchelor (ed.), The art of literary biography. Oxford: Clarendon Press.

QUINTAIS, Luís, (2008), "A ekphrasis como meta-representação", in Relâmpago, no 23, pp. $94-96$.

RASTEIRO, João, "Poetas: Tiago Veiga, meu avô e eu!" (texto inédito).

RODRIGUES, Ernesto, "Poesia portuguesa: uma década "1996-2006)", in http://www.msmidia.com/conexao/3/cap4.pdf (acedido em 9 de janeiro de 2012).

SEQUEIRA, Maria do Carmo Castelo Branco V. de, "Identidade e suas ficções (a propósito de Tiago Veiga - Uma Biografia, de Mário Cláudio)", in Impossibilia, no 2, Octubre, 2011, pp. 96-106 (http://www.impossibilia.org/static/descargas/numero-2/identidade-suas-ficcoes-proposito-tiago-veiga-biografia-mario-claudio-maria-carmo-castelo-branco-vilaca-sequeira.pdf) (acedido em 9 de janeiro de 2012). 
The world book encyclopedia. (1976), Vol. 2. Chicago: World Book, ("Biography").

VEIGA, Tiago, (2005), Os sonetos italianos de Tiago Veiga. Org. e Prefácio Mário Cláudio. Porto: Asa.

___, (2008), Gondelim de Tiago Veiga. Vila Nova de Famalicão: Quasi.

__-, (2010), Do espelho de Vénus. Lisboa: Arcádia.

WINSLOW, Donald J., (1980), Life-writing. A glossary of terms in biography, autobiography, and related forms. Honolulu: Biographical Research Center/University of Hawaii. 